\title{
A new occurrence of the Late Triassic archosaur Smok in southern Poland
}

Grzegorz Niedźwiedzki and Ewa Budziszewska-Karwowska

Acta Palaeontologica Polonica 63 (4), 2018: 703-712 doi:https://doi.org/10.4202/app.00505.2018

Two isolated teeth, a dorsal vertebra, fragments of a humerus and femur, a fragmentary pubic "boot" and part of an ischium shaft, identified here as belonging to a large predatory archosaur were discovered in the Upper Triassic site at Marciszów near Zawiercie (southern Poland). Comparisons of the new fossils from Marciszów with the dorsal vertebrae, pubic "boot", ischium and femur of the theropod-like Smok wawelski from Lisowice (Silesia) reveal that the two taxa are very similar. Nevertheless, due to the lack of more diagnostic elements (e.g., braincase or cranial elements), we prefer to consider all described specimens from Marciszów as Smok sp. Smok sp. shares a low mound-like, anterior trochanter with trochanteric shelf on the femur, a massive pubic "boot" with a distinct depression (= bevelled area), and a transversely lenticular ischium shaft in cross-section with $S$. wawelski. Some observed characters of the dorsal vertebra (e.g., lack of some lamina, shape and position of zygapophyses), however, are different from $S$. wawelski and may also suggest that the new findings represent a second species of the genus in the Upper Triassic of Poland. The discovery of Smok sp. at Marciszów is significant because it is the second example of the co-occurrence of this genus with: (i) bones of a large dicynodont; and (ii) record of gnawed tetrapod bones. The discovery of Smok sp. and the lack of significant morphologic divergence from $S$. wawelski suggest that this taxon is the only large-bodied predator currently known from the Upper Triassic of Poland. This new evidence expands the record of the genus and contributes, in some measure, to our knowledge of the stratigraphical distribution of large predatory archosaurs from the Polish Upper Triassic bone-bearing levels.

Key words: Diapsida, Archosauromorpha, Archosauria, Late Triassic, Poland, Silesia.

Grzegorz Niedźwiedzki [grzegorz.niedzwiedzki@ebc.uu.se], Subdepartment of Evolution and Development, Department of Organismal Biology, Uppsala University, Norbyvägen 18A, SE-752-36, Uppsala, Sweden. Ewa Budziszewska-Karwowska [ebudzisz@wnoz.us.edu.pl], Museum of Earth Sciences, Faculty of Earth Sciences, University of Silesia, Będzińska 60 Street, PL-41-200 Sosnowiec, Poland. 
This is an open-access article distributed under the terms of the Creative Commons

Attribution License (for details please see creativecommons.org), which permits unrestricted use, distribution, and reproduction in any medium, provided the original author and source are credited.

Faril Full text $(586.5 \mathrm{kB})$ 